\title{
Prevelance of Pulmonary Atherosclerosis in Patients With Chronic Thromboembolic Pulmonary Hypertension
}

\author{
Tarik Kivrak ${ }^{1 *}$, Hasan Ata Bolayir² ${ }^{2}$ Batur Gönenc Kanar ${ }^{3}$, Dursun Akaslan², Alper Kepez ${ }^{3}$, \\ Bülent Mutlu ${ }^{3}$ and Bedrettin Yildizeli ${ }^{4}$ \\ ${ }^{1}$ Department of Cardiology, Firat University Hospital, Elazig, Turkey \\ ${ }^{2}$ Department of Cardiology, Sivas State Hospital, Sivas, Turkey \\ ${ }^{3}$ Department of Cardiology, Marmara University Hospital, Istanbul, Turkey \\ ${ }^{4}$ Department of Thoracic Surgery, Marmara University Hospital, Istanbul, Turkey
}

Received: 25 April, 2017; Accepted: 04 June, 2017; Published: 14 June, 2017

*Corresponding author: Tarik Kivrak, Department of Cardiology, University of Firat, Firat University Hospital, Elazig, Turkey, Tel: 05053729945, Fax: 03464444458; E-mail: tarikkivrak@gmail.com

\begin{abstract}
Conjunctive: The aim of our study was to determine the prevalence of pulmonary atherosclerosis in patients with Chronic Thromboembolic Pulmonary Hypertension (CTEPH) who underwent Pulmonary Endarterectomy (PEA).

Methods: One hundred twenty-eight patients with CTEPH who underwent PEA included in our study. Pathologic examination performed to the excised chronic thromboembolic material for the presence of atherosclerosis.

Results: Pathologic specimens of 65 patients (50.8\%) displayed atherosclerosis in our study. There were no evident differences between the group with pulmonary atherosclerosis and group without pulmonary atherosclerosis regarding the prevalence of smoking, hypertension, diabetes, hypercholesterolemia, high sensitive CRP (hsCRP) and the neutrophile-lymphocyte ratio (N/L ratio).

Conclusions: Pulmonary atherosclerosis seems to be a common finding in patients with CTEPH. Based on this observation it might be suggested that pathophysiological association exists between venous thromboembolism and atherosclerosis.
\end{abstract}

Keywords: Atherosclerosis; Pulmonary Endarterectomy; Chronic Thromboembolic; Venous Thrombosis

Abbreviations: CTEPH: Chronic Thromboembolic Pulmonary Hypertension; VTE: Venous thromboembolism; N/L ratio: Neutrophile-lymphocyte ratio.

\section{Introduction}

Atherosclerosis and venous thromboembolism (VTE) are different pathological entities with different pathophysiology and treatment modalities. Pathologically, venous thrombosis has been shown to be rich in red blood cells whereas arterial thrombi are mainly composed of platelets. In agreement with, this the role of antiplatelet and anticoagulant agents in the prevention and treatment of both entities is different [1]. However, recent studies have suggested associations between venous thromboembolism and arterial thrombosis [2]. Trials have shown that patients with atherosclerosis may be at increased risk of venous thromboembolism due to increased level of thrombogenic factors [3]. In one of these studies, higher prevalence of coronary artery calcium observed in patients with venous thrombosis compared with controls which suggest coronary artery disease as an independent risk factor for VTE [4]. Patients with venous thrombosis were found to have a significantly increased risk of stroke and myocardial infarction during the first year after the thrombotic event in a population-based cohort study [5]. We aimed to evaluate the association between atherosclerosis and VTE by retrospectively examining the pulmonary endarterectomy biopsy material of patients with CTEPH for the presence of atherosclerosis in the present study.

\section{Materials and Methods}

The study was the single center and retrospective study. Pathologic specimens of CTEPH patients who underwent PEA between August 2010 and June 2013 examined for the presence of atherosclerosis. Data of 128 patients used for the analysis. Demographic data, cardiovascular risk factors and laboratory findings of all patients recorded. The ethic committee at the Marmara University of Medicine approved the study protocol, and all study participants provided written informed consent. All procedures used in this study were by institutional guidelines. We analyzed pulmonary endarterectomy material regarding pulmonary atherosclerosis. Atherosclerosis was defined intimal thickness and plaque of pulmonary artery. We will see typical appearing atheromas in the pulmonary artery and foam cells containing lipid and usual features of an atherosclerotic plaque. There are three major changes in the pulmonary artery wall.1Infiltration by smooth cells in intima layer.2- Proliferation of smooth muscle cells.3- proliferation of fibroblasts and macrophages in adventia layer (Figure 1 and 2). In CTEPH 
organized thrombi replace the intima of proximal or distal elastic pulmonary arteries and attach to the medial layer, causing variable degrees of stenosis or complete occlusion of the lumen. Changes similar to pulmonary arterial hypertension can develop in the nonoccluded areas, and collateral vessels from the systemic circulation may grow to reperfuse areas of complete obstruction [6].

Data expressed as the mean \pm standard deviation for continuous variables and frequencies or proportions for categorical variables. Continuous demographic variables compared between the two groups using the Mann-Whitney U-test, and categorical variables were compared using Pearson's chi-squared or Fisher's exact test. All statistical analyses were performed using SPSS for Windows (version 18.0; SPSS, Chicago, IL, USA). All p values reported are two-sided, and a value of $<0.05$ was considered statistically significant.

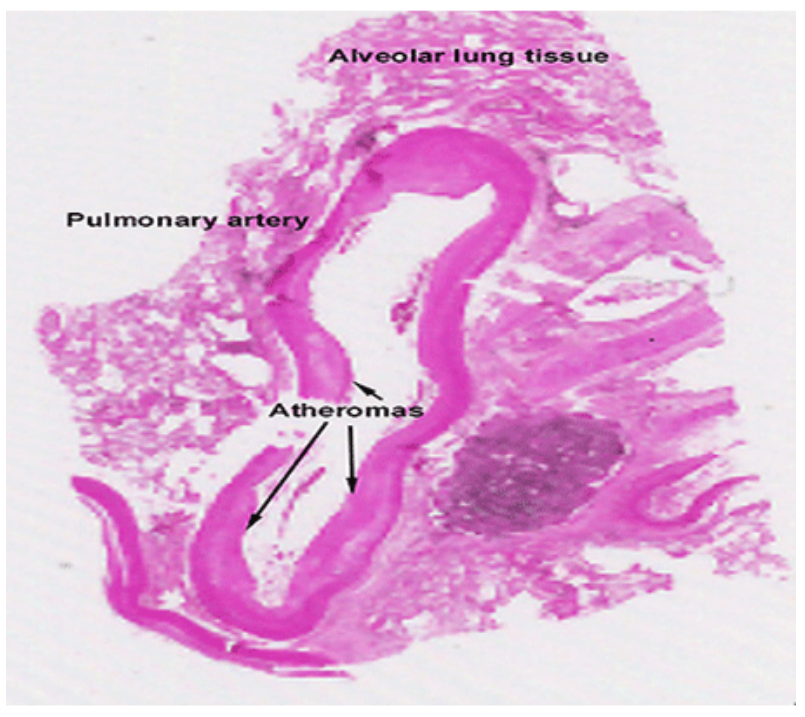

Figure 1: Atherosclerosis image in Pulmonary Artery

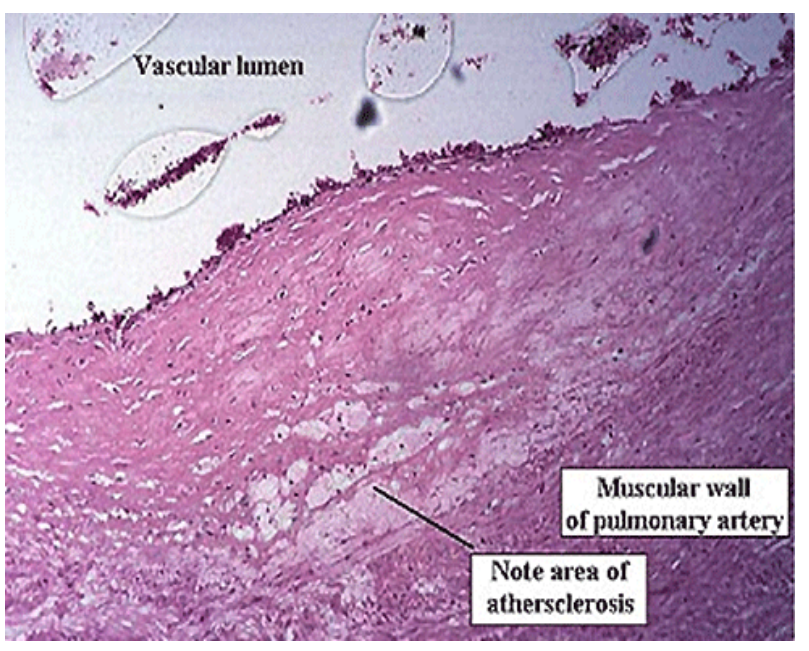

Figure 2: Atherosclerosis image in Pulmonary Artery

\section{Results}

Demographic characteristics of the study population shown in Tables 1-3. The Pathologic specimen of 65 patients (\%50.8) displayed atherosclerosis, and the study population divided into two groups based upon the presence of pulmonary atherosclerosis (Patients with atherosclerosis-Group A; non-atherosclerosisGroup B). Characteristics between group A and group B shown in Table 4. In our study; diabetes, family history, and smoking were less determined in patients with atherosclerosis (26 (\%20.3), 9 (\%7), 18 (\%14.1) ( $\mathrm{p}$ values < 0.05)). There were no significant differences in the prevalence of smoking, hypertension, diabetes, hypercholesterolemia, hsCRP, N/L ratio, ages between patients with atherosclerosis and non-atherosclerosis (Table 5, all $P>$ 0.05).

Table 1: Demographic characteristics of study patients

\begin{tabular}{|c|c|}
\hline & $\begin{array}{l}\text { Number of Patients } \\
(n=128)\end{array}$ \\
\hline Age (years) & $53 \pm 15.79$ \\
\hline Sex (male) & 59 \\
\hline Coronary Artery Disease & 30 \\
\hline Diabetes & 36 \\
\hline Hypertension & 52 \\
\hline Hyperlipidemia & 48 \\
\hline
\end{tabular}

Table 2: Medication characteristics of the study population

\begin{tabular}{|c|c|}
\hline Group of drugs & $\begin{array}{c}\text { Number of Patients } \\
\text { (n=128) }\end{array}$ \\
\hline Furosemid & 87 \\
Spiranolacton & 12 \\
Spiranolacton+Hydrochlorotiazid & 73 \\
Warfarine & 128 \\
Statin & 48 \\
ACEI & 38 \\
ARB & 14 \\
Beta-blocker & 56 \\
Digoxin & 16 \\
Nitrates & 17 \\
\hline Asetil salisilic aside & 24 \\
\hline
\end{tabular}

Table 3: Average of laboratory in the study population

\begin{tabular}{|c|c|c|}
\hline Parameters & Mean & $\begin{array}{c}\text { Standard } \\
\text { Deviation }\end{array}$ \\
\hline High-Density Lipoprotein & 42.97 & 13.56 \\
\hline Low-Density Lipoprotein & 111.1 & 43.99 \\
\hline Triglyceride & 113.3 & 49.17 \\
\hline Total Cholesterol & 175.16 & 53.74 \\
\hline High sensitiveCRP & 24.7 & 15.7 \\
\hline Mean Platelet Volume & 8.48 & 1.17 \\
\hline Neutrophile-Lymphocyte ratio & 3.87 & 3.38 \\
\hline
\end{tabular}




\begin{tabular}{|c|c|c|c|}
\hline Table 4: Characteristics of group A and group B \\
\hline Parameters & Group A & Group B & $\boldsymbol{p}$ value \\
\hline Atherosclerosis & 65 & 63 & 0.399 \\
\hline Family History & 9 & 119 & 0.005 \\
\hline Diabet & 10 & 26 & 0.03 \\
\hline Smoking & 18 & 83 & 0.04 \\
\hline Hypertension & 13 & 15 & 0.121 \\
\hline Gender & Male (46.1\%) & Male (53.9\%) & 0.237 \\
\hline
\end{tabular}

\section{Discussion}

Our purpose of study is determined that prevelance of atherosclerosis in patients with venous thrombosis. Because it is to determine more clearly the relationship between venous thrombosis and arterial atherosclerosis. To the best of our knowledge, this is the first study to demonstrate that the prevalence of atherosclerosis in these patients. We have also shown that common features of patients with atherosclerosis. It is already known that atherothrombosis and deep venous

Table 5: Differences between patients with atherosclerosis and non-atherosclerosis

\begin{tabular}{|c|c|c|c|}
\hline Parameters & Atherosclerosis (Group A) & $\begin{array}{c}\text { Noatherosclerosis } \\
\text { (Group B) }\end{array}$ & p-value \\
\hline Age & $52.98 \pm 15.005$ & $50.56 \pm 17.98$ & 0.387 \\
\hline Low-Density Lipoprotein & $112 \pm 40$ & $113 \pm 42$ & 0.934 \\
\hline Triglyceride & $109 \pm 36$ & $129 \pm 62$ & 0.166 \\
\hline Total Cholesterol & $174 \pm 49$ & $182 \pm 51$ & 0.567 \\
\hline High sensitive CRP & $36 \pm 21$ & $40 \pm 23$ & 0.832 \\
\hline Mean Platelet Volume & $8.3 \pm 1$ & $8.5 \pm 1.2$ & 0.3 \\
\hline Neutrophile-Lymphocyte Ratio & $4.8 \pm 6.8$ & $4.6 \pm 5.5$ & 0.907 \\
\hline Thrombin-antithrombin complex (TAT)(ng/ml) & $6.53 \pm 8.73$ & $6.44 \pm 7.79$ & 0.456 \\
\hline Plasmin-alpha 2-plasmin inhibitor complex $(P I C)(\mu \mathrm{g} / \mathrm{ml})$ & $1.22 \pm 1.56$ & $1.23 \pm 1.45$ & 0.234 \\
\hline
\end{tabular}

thrombosis have many common risk factors. These data state that some risk factors for arterial thrombosis, such as obesity and diabetes, may also have a role in venous thrombosis, while uncertainty remains for other risk factors such as smoking, hypertension, and hyperlipidemia. The results of the present study indicate that patients with chronic pulmonary thromboembolism have an increased prevalence of atherosclerosis. These findings suggested that venous thromboembolism and associated with pulmonary atherosclerosis, independent of age and general cardiovascular disease risk factors in our study.

Our study is the first study which evaluates the prevalence of pulmonaryatherosclerosis in patients with CTEPH.Theassociation between venous thromboembolism and atherosclerosis and first reported in 2003 [7]. That trial was determined that relation between atherosclerosis and venous thrombosis. Prandoni et al. followed patients with vein thrombosis, and they reported that at least one arterial event took place in $15.1 \%$ of patients after a median follow-up of about four years [8]. Another study observed a higher mortality rate associated with arterial disease in patients with venous thrombosis than that expected in general population [9]. Increased incidence of venous thrombosis also reported in patients with arterial disease in a cohort study [10]. Another population-based cohort study assessed the risk of subsequent arterial disease among 25,000 patients with deep venous thrombosis, 16,000 patients with pulmonary embolism and $1,63,500$ population controls. Patients with venous thrombosis were found to have a substantially increased risk of arterial disease in that study [5]. Atherosclerosis may prescribe aa greater risk for venous thrombosis development, but conditions resulting from atherosclerosis may predispose to venous thrombosis because of the potential for associated morbidity, immobility, and surgery. Atherosclerosis is progressive that can lead to endothelial damage and coagulation system activation systemically thereby promoting thrombus formation in the veins. However venous thrombosis may be a significant atherosclerosis risk factor. It is a common pathologic process.

\section{Conclusion}

Our results have challenged the notion of different nature of arterial and venous thromboembolism. Based on our observations it may be suggested that patients with venous thrombosis should be examined for asymptomatic atherosclerosis. We think that 
atherosclerosis' prevalence higher than our estimate in patients with venous thrombosis. Aggressive risk factor modification and medications as antiplatelet agents and statins might have a role in the prevention of both venous thrombosis and arterial events in patients with venous thrombosis and atherosclerosis. Future studies are needed to clarify the nature of this association, assess its extent, and evaluate its implications for clinical practice.

\section{Acknowledgement}

\section{Figure 1-2:}

Carolyn G. Begley, OD, MS, and Mark Braun, MD. Page design and coding: Terri Greene Indiana University School of Optometry. Copyright (C) 1998, The Trustees of Indiana University

\section{References}

1. Franchini M, Mannucci PM. Venous and arterial thrombosis: different sides of the same coin? Eur J Intern Med. 2008;19(7):476-481. doi: 10.1016/j.ejim.2007.10.019

2. Agnelli G, Becattini C. Venous thromboembolism and atherosclerosis: common denominators or different diseases? J Thromb Haemost 2006;4(9):1886-1890. doi: 10.1111/j.1538-7836.2006.02138.x

3. Marutsuka K, Hatakeyama K, Yamashita A, Asada Y. Role of thrombogenic factors in the development of atherosclerosis. J Atheroscler Thromb. 2005;12(1):1-8.

4. Hong C, Zhu F, Du D, Pilgram TK, Sicard GA, Bae KT. Coronary artery calcification and risk factors for atherosclerosis in patients with venous thromboembolism. Atheroscler. 2005;183(1):169-174. doi: 10.1016/j.atherosclerosis.2005.03.047
5. Sorensen HT, Horvath-Puho E, Pedersen L, Baron JA, Prandoni P. Venous thromboembolism and subsequent hospitalization due to acute arterial cardiovascular events: a 20-year cohort study. Lancet. 2007;370(9601):1773-1779. doi: 10.1016/S0140-6736(07)61745-0

6. Galiè N, Hoeper MM, Humbert M, Torbicki A, Vachiery JL, Barbera JA, et al. Task Force for Diagnosis and Treatment of Pulmonary Hypertension of European Society of Cardiology (ESC); European Respiratory Society (ERS); International Society of Heart and Lung Transplantation (ISHLT). Guidelines for the diagnosis and treatment of pulmonary hypertension. Eur Respir J. 2009;34(6):1219-1263. doi: 10.1183/09031936.00139009

7. Prandoni P, Bilora F, Marchiori A, Bernardi E, Petrobelli F, Lensing AW, et al. An association between atherosclerosis and venous thrombosis. N Engl J Med. 2003; 348(15):1435-1441. doi: 10.1056/NEJMoa022157

8. Prandoni P1, Ghirarduzzi A, Prins MH, Pengo V, Davidson BL, Sørensen $\mathrm{H}$, et al. Venous thromboembolism and the risk of subsequent symptomatic atherosclerosis. J Thromb Haemost. 2006;4(9):18911896. doi: 10.1111/j.1538-7836.2006.02058.x

9. Schulman S, Lindmarker P, Holmstrom M, et al. Post-thrombotic syndrome, recurrence, and death ten years after the first episode of venous thromboembolism treated with warfarin for six weeks or six months. J Thromb Haemost. 2006;4(4):734-742. doi: 10.1111/j.15387836.2006.01795.x

10. Eliasson A, Bergqvist D, Björck M, Acosta S, Sternby NH, Ogren M. Incidence and risk of venous thromboembolism in patients with verified arterial thrombosis a population study based on 23.796 consecutive autopsies. J Thromb Haemost. 2006; 4(9):1897-1902. doi: 10.1111/j.1538-7836.2006.02152.x 